\title{
Desenvolvimento de um protótipo para classificação de perfis de pulverização utilizando processamento digital de sinais e redes neurais artificiais
}

\author{
Servílio Souza de Assis ${ }^{1}$, Bruno Alberto Soares Oliveira ${ }^{1}$, Robson Shigueaki \\ Sasaki $^{2}$ and Francisco Heider Willy dos Santos ${ }^{2}$
}

${ }^{1}$ Universidade Federal de Minas Gerais and ${ }^{2}$ Instituto Federal de Minas Gerais

*servilio.souza@gmail.com; brunoalbertobambui@gmail.com; robson.sasaki@ifmg.edu.br; francisco.santos@ifmg.edu.br

Recebido: 16/08/2018. Revisado: 18/01/2019. Aceito: 13/03/2019.

\begin{abstract}
Resumo
Um dos grandes desafios da agricultura é o uso racional de agrotóxicos na prevenção e proteção das culturas contra doenças e pragas, a fim de evitar a aplicação demasiada de agentes químicos nas lavouras, evitando-se danos ao meio ambiente e a saúde humana. Atualmente, as técnicas utilizadas para avaliação da qualidade de pulverização se baseiam na análise do tamanho das gotas que são aplicadas através de etiquetas hidrossensíveis Neste trabalho foi desenvolvida uma bancada de testes, que permite a simulação do funcionamento de pontas de pulverização, e um sistema de aquisição, condicionamento e análise de dados para realização de um estudo de sensoriamento laser aplicado na identificação de espectros de gotas. Além disso, foi proposto e avaliado um método de classificação baseado em Transformada Rápida de Fourier e Redes Neurais Artificiais. A metodologia utilizada para a avaliação da técnica proposta consiste na aquisição e análise de um sinal de luz proveniente de um raio laser interceptado por um spray de água criado pela ponta, e classificação do padrão com base nas amplitudes do espectro de frequências, obtidos a partir da Transformada Discreta de Fourier do sinal. Para a classificação, foi utilizada uma RNA do tipo Perceptron de Múltiplas Camadas a fim de identificar dois diferentes padrões de pulverização, classificando os espectros de gotas em duas classes, névoa ou jato. Foi feita a validação cruzada e a técnica proposta apresentou $91 \%$ de acurácia. Assim, foi possível concluir que através do método proposto é possível identificar diferentes espectros de gotas.
\end{abstract}

Palavras-Chave: Pulverização de Agrotóxicos; Sensoriamento Laser; Transformada Rápida de Fourier.

\begin{abstract}
One of the major challenges of agriculture is the rational use of agrochemicals in crop to prevention and protection against diseases and pests, in order to avoid the excessive application of chemical agents in crops, avoiding damages to the environment and human health. Currently the techniques used to evaluate the quality of the spray are based on the analysis of droplet size that are applied through hydrosensitive labels. In this work a test bench was developed, which allows the simulation of the operation of spray nozzles, and a data acquisition, conditioning and analysis system for conducting a laser sensing study applied to the identification of droplet spectra. In addition, a classification method based on Fast Fourier Transform and Artificial Neural Networks was proposed and evaluated. The methodology used for the evaluation of the proposed technique consists of the acquisition and analysis of a light signal from a laser beam intercepted by a water spray created by the nozzle, and classification of the pattern based on the frequency spectrum amplitudes obtained from of the Fourier discrete signal transform. For the classification, a ANN Multilayer Perceptron was used to identify two different spray patterns, classifying the drop spectra into two classes, mist or jet. Cross-validation was performed and the proposed technique presented $91 \%$ accuracy. Thus, it was possible to conclude that through the proposed method it is possible to identify different spectra of drops.
\end{abstract}

Key words: Fast Fourier Transform; Laser Sensor; Pesticide spraying. 


\section{Introdução}

A agricultura possui grande destaque na economia do Brasil tendo em vista que uma grande variedade de culturas é produzida no país. Desta maneira, há uma demanda constante por investimentos em tecnologia e inovação a fim de aprimorar cada vez mais este setor. De acordo com dados publicados pela CNA (2016), o agronegócio brasileiro tinha representação no produto interno bruto do país de $23 \%$ ao final de 2016. O setor agrícola é responsável por $48 \%$ das exportações do país.

A prática do cultivo agrícola é passível de alguns problemas, como doenças, pragas e plantas daninhas. Hoje, esses problemas podem ser contornados com a utilização de defensivos agrícolas.

Segundo da Cunha (2008), há um consenso social que os agrotóxicos são prejudiciais ao homem. Apesar do uso desses produtos terem contribuído fortemente com a agricultura, é importante que as aplicações sejam feitas de forma racional, visando a proteção das plantas, saúde humana e animal, prevenção de contaminação do solo e da água e o surgimento de pragas, doenças ou plantas daninhas mais resistentes.

A pulverização é um processo físico cujo objetivo é transformar um líquido em gotas. De acordo com Matthews (2002), o objetivo da tecnologia de aplicação de agrotóxicos é colocar a quantidade certa de ingrediente ativo no alvo, com a máxima eficiência e da maneira mais econômica, afetando o mínimo possível o meio.

De acordo com Hipkins et al. (2009), a deriva dos produtos químicos pode desviar parte dos ativos do alvo pretendido, o que consequentemente reduz a eficácia e deposita agrotóxicos onde não há necessidade. Isso pode ocasionar danos ambientais e econômicos, como exposição de pessoas aos agentes químicos, ferimentos à vegetação, danos à vida selvagem, deposição de resíduos ilegais nas culturas e contaminação do abastecimento de água. Gotas muito finas podem favorecer a deriva (Rodrigues et al.; 2015) e gotas grossas favorecem o escorrimento (Silva et al.; 2014). Em relação a cobertura da cultura pelos ativos, gotas finas tendem a aumentar a área de recepção alvo em relação a gotas grossas.

Segundo Steden (1992), o tamanho das gotas é importante devido a influência da mesma na dificuldade de alcançar o alvo. Assim, surge o problema do monitoramento da qualidade da pulverização. No ato da pulverização, através de ajustes de pontas de pulverização hidráulica e pressão de trabalho, deve-se selecionar o tamanho de gota correto de acordo com o princípio ativo do produto aplicado e a cobertura desejada, minimizando as perdas para o meio ambiente, além de monitorar a persistência do espectro desejado durante toda a aplicação do agrotóxico na cultura.

Baseado neste contexto, o respectivo trabalho aborda uma proposta de tecnologia que pode ser utilizada no controle de qualidade de pulverização de agrotóxicos, tendo como principal objetivo propor o desenvolvimento de um protótipo de laboratório para simulação, captura e análise de dados e um programa para classificação de diferentes espectros de gotas utilizando sinais gerados por um sensor laser.

\subsection{Justificativa e Importância do Trabalho}

Acredita-se que a técnica proposta possibilitará a análise de qualidade de pulverização, visando a prevenção de problemas relacionados à má aplicação de ativos químicos nas plantações, como perdas de material, contaminação dos solos, comprometimento da saúde das plantas e, consequentemente, perdas na produção.

Tal análise terá como base a identificação de espectros de gotas adequados para diferentes situações no campo, o que poderá permitir o ajuste da máquina de pulverização para um espectro de gotas desejado.

O estudo será uma base para a construção de soluções para monitoramento do espectro de gotas, que é influenciado por várias condições operacionais, a fim de garantir maior qualidade nas aplicações de defensivos agrícolas.

A técnica proposta poderá também ser estudada para aplicações em soluções de problemas de outras naturezas, utilizando processamento de sinais e análise no domínio da frequência.

\subsection{Estado da Arte}

A técnica proposta no presente trabalho já foi abordada em diferentes trabalhos para resolução de outros problemas, conforme apreciados a seguir.

Nääs et al. (2008) desenvolveram um método baseado no uso de RNAs, capaz de reconhecer vocalizações relacionadas com padrões indicativos de bem-estar de suínos. A análise dos sons foi feita com base nos espectros de frequência.

Matos et al. (2009) desenvolveram uma metodologia para detectar e classificar curtoscircuitos em alimentadores de sistemas de distribuição de energia elétrica, com base em análise de registros oscilográficos através de transformada discreta de Fourier e RNA.

Gothwal et al. (2011) desenvolveram um método para analisar um sinal de eletrocardiograma com o intuito de extrair características para classificação de batimentos cardíacos com diferentes arritmias. No trabalho, foi utilizada uma RNA em conjunto com a técnica de FFT para realização da classificação.

Rufino (2011) utilizou o efeito de espalhamento de luz infravermelha, proveniente de um laser, para detectar, medir e controlar a concentração de partículas em suspensão no ar. Em seu experimento, foi avaliada a linearidade entre o sinal obtido e a concentração de partículas obtendo um coeficiente de determinação de 99,2\%.

No que concerne ao controle de qualidade, a avaliação da qualidade de pulverização no campo é geralmente feita através de etiquetas hidrossensíveis, as quais são colocadas na planta para capturar as gotas de agrotóxico e são analisadas após a aplicação dos ativos. A análise é feita visualmente ou com a utilização de softwares específicos para análise de imagens.

Quando se deseja realizar a análise do espectro de gotas detalhada, pode-se empregar o sensor a laser. Existem soluções comerciais baseadas em sensoriamento laser que fazem a análise através de um raio laser que intercepta o jato de agrotóxicos, gera um sinal de leitura e verifica o espectro de gotas. 
Estes sensores são de utilização em laboratório e possuem altos custos.

\section{Referencial Teórico}

O presente capítulo apresenta o referencial teórico necessário para realização do entendimento do trabalho desenvolvido. Cada seção apresenta um conceito utilizado na metodologia de desenvolvimento.

\subsection{Fenômenos da Luz}

Em 1801, Thomas Young demonstrou pela primeira vez a natureza ondulatória da luz, com base na observação de interferência de duas fontes coerentes ao iluminar duas fendas estreitas e paralelas com a mesma fonte de luz. Esta abordagem chegou ao auge em 1860, com estudos de Maxwell para as ondas eletromagnéticas. Em 1905, Albert Einstein propôs, pela primeira vez, a natureza corpuscular da luz, em sua explicação para o efeito fotoelétrico.

Conforme explicado por Macedo and Tipler (2000), as propriedades ondulatórias da luz regem sua propagação e as propriedades corpusculares regem a troca de energia com a matéria. A dualidade ondapartícula também é encontrada na propagação de algumas entidades partículas, como os elétrons.

\subsubsection{Propagação da Luz}

Muito antes de Maxwell estabelecer teoricamente que a luz se propaga através de ondas eletromagnéticas, sua propagação era descrita empiricamente por dois princípios atribuídos pelo físico Christiaan Huygens (1629-1695) e pelo matemático Pierre de Fermat (1629-1665).

O princípio de Huygens é uma representação de ondas em que cada ponto de uma frente de onda apresenta comportamento de uma nova fonte de ondas, as quais se propagam para além da região já alcançada pela onda original e com a mesma frequência. A Figura 1 representa o princípio de Huygens.
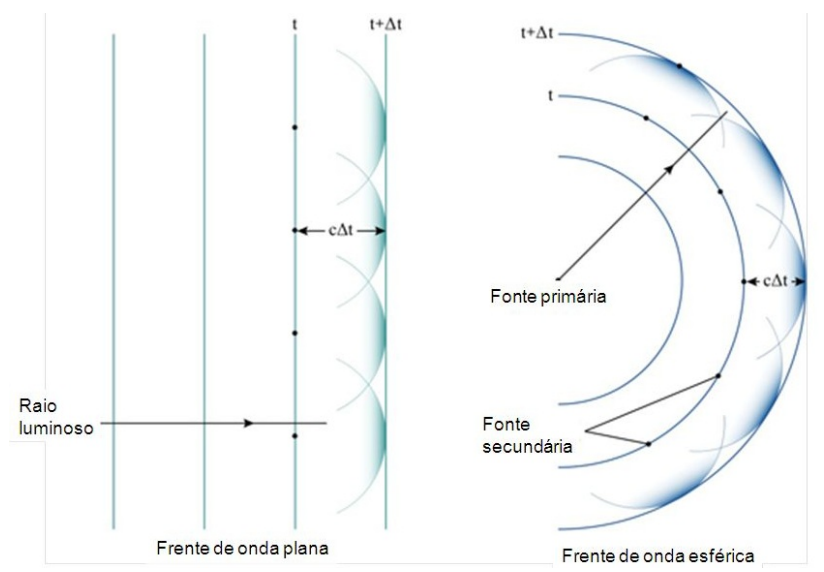

Figura 1: Princípio de Huygens Fonte: Adaptado de Slide Player

A distância entre duas frentes de onda emitidas por uma fonte é equivalente ao produto da velocidade da luz (c) pelo intervalo de tempo $(\Delta t)$ entre o lançamento de uma e outra.

De acordo com Macedo and Tipler (2000), o princípio de Fermat enuncia que a trajetória seguida pela luz viajando de um ponto a outro é tal que o tempo da viagem é o menor possível, isto é, a luz percorre a trajetória mais rápida.

\subsubsection{Reflexão e Refração}

A velocidade da luz no vácuo é de aproximadamente $3 \cdot 10^{8} \frac{\mathrm{m}}{\mathrm{s}}$. Já em meios transparentes, como ar, água ou vidro a velocidade é menor. Um meio transparente possui associado um índice de refração representado pela letra $n$, o qual representa a razão entre a velocidade da luz no vácuo e a velocidade no meio em questão.

$$
n=\frac{c}{v}
$$

em que c representa a velocidade da luz no vácuo e v representa a velocidade da luz no meio.

Quando um feixe de luz incide sobre uma interface que separa dois meios diferentes, parte desta luz é refletida e parte atravessa a interface, entrando no segundo meio. Se o feixe de luz incidente não for perpendicular a interface, a parcela transmitida não possui mesmo ângulo que o feixe incidente. Essa variação de ângulo é chamada de refração. A Figura 2 mostra o comportamento de um feixe de luz incidente na interface entre dois meios.

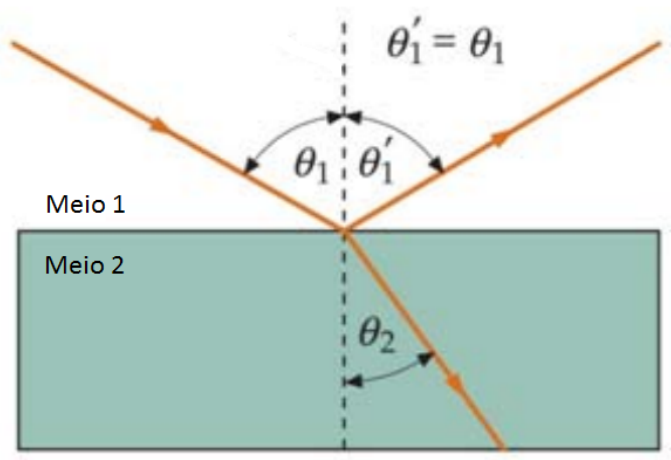

Figura 2: Reflexão e refração de um feixe de luz incidente em uma interface entre dois meios Fonte: Adaptado de Macedo and Tipler (2000)

A luz incidente apresenta um ângulo $\theta_{1}$ em relação a reta normal. Parte da luz é refletida com ângulo $\theta_{1}{ }^{\prime}$, que é igual a $\theta_{1}$. A luz refratada apresenta ângulo $\theta_{2}$, o qual é diferente de $\theta_{1}$. A relação entre os ângulos de incidência e de refração é dada pela lei de Snell:

$$
n_{1} \cdot \sin \theta_{1}=n_{2} \cdot \sin \theta_{2},
$$

em que $n_{1}$ e $n_{2}$ são os índices de refração dos meios 1 e 2 , respectivamente. 


\subsubsection{Laser}

A luz no formato de laser é caracterizada por ser altamente potente, devido ao fato de apresentar grande concentração de energia em pequenas áreas. Além disso, a luz do raio laser apresenta as seguintes características.

- Monocromático: constituído por radiações de uma única frequência.

- Coerente: as ondas apresentam relação de fase constante entre si.

De acordo com Rodrigues (2007), devido a suas propriedades especiais, o laser é aplicado em vários segmentos da sociedade: na medicina (cirurgias), na indústria (corte de metais, medição de distâncias), comerciais (fibras ópticas, leitores de código de barras), dentre outras.

\subsection{Técnicas de Análise de Pulverização}

Segundo Hipkins et al. (2009), ao escolher o tamanho das gotas de agrotóxicos dos ativos químicos para aplicações de pulverização, deve ser considerada a cobertura necessária e o potencial de deriva. Apesar de gotas pequenas fornecerem maior cobertura das plantas pelo agente, gotas maiores são menos propensas a deriva.

Conforme discutido por Nordby and Skuterud (1974), o tamanho da gota é influenciado pelo tipo de ponta utilizada na pulverização e pela pressão de trabalho. Consequentemente, essas variáveis também influenciam na vazão do produto, deposição no alvo, uniformidade, eficácia e risco de deriva.

De acordo com a norma ASABE S572.1 Droplet Size Classification, o tamanho das gotas são rotulados por faixas, conforme mostrado na Tabela 1.

Tabela 1: Faixas de tamanho de gotas

\begin{tabular}{lcc}
\hline Categoria & Símbolo & Diâm. Médio $(\mu \mathrm{m})$ \\
\hline Extremamente Fina & EF & $<60$ \\
Muito Fina & VF & $61-105$ \\
Fina & F & $106-235$ \\
Média & M & $236-340$ \\
Grossa & C & $341-403$ \\
Muito Grossa & VC & $404-502$ \\
Extremamente Grossa & XC & $503-665$ \\
Ultra Grossa & UC & $>665$ \\
\hline
\end{tabular}

A seguir, são apresentadas as técnicas para análise do espectro de gotas.

\subsubsection{Etiquetas Hidrossensíveis}

As etiquetas hidrossensíveis são etiquetas que possuem uma camada sensível ao líquido dos agrotóxicos. Quando uma gota entra em contato com a superfície da etiqueta, ocorre uma reação química que resulta uma mudança de cor na região afetada. Geralmente, as etiquetas são amarelas e a cor resultante da reação química é azul.

A utilização consiste na fixação de etiquetas em algumas partes das plantas alvo antes de realizar a aplicação dos ativos. Após a pulverização, as etiquetas são recolhidas e as análises são feitas visualmente ou com softwares de análise de imagens. A Figura 3 apresenta um exemplo de etiqueta hidrossensível.
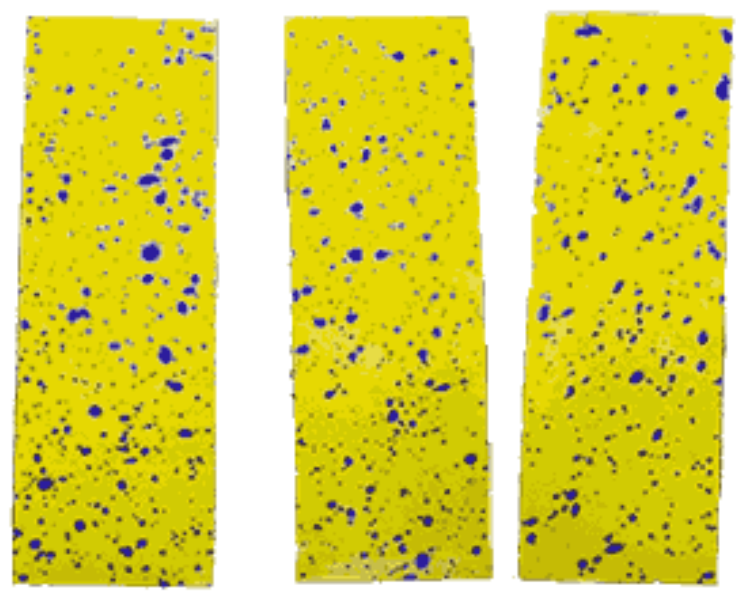

Figura 3: Etiquetas hidrossensíveis após aplicação de pulverização

Fonte: Canal Agrícola

Um grande problema das etiquetas é que a análise só pode ser feita após a aplicação, sendo difícil de prevenir espectros de gotas indesejáveis.

\subsubsection{Soluções Comerciais para Análise Laboratorial}

Existem soluções comerciais de laboratório que fazem análise do espectro de gotas utilizando sensoriamento laser. Cunha et al. (2007) utilizaram uma solução comercial para avaliar o espectro de gotas de diferentes pontas de pulverização hidráulica. O equipamento utilizado foi o Spraytec (Malvern Spraytec Real Time Droplet Sizing System, Malvern Instruments, Malvern, England).

Nessas análises, um feixe de luz atravessa o spray de agrotóxicos e chega a um sensor. De acordo com o tamanho e a densidade de gotas que interceptam o laser, o sinal detectado pelo sensor é alterado. A Figura 4 mostra o esquema de um sensor laser para análise de gotas.

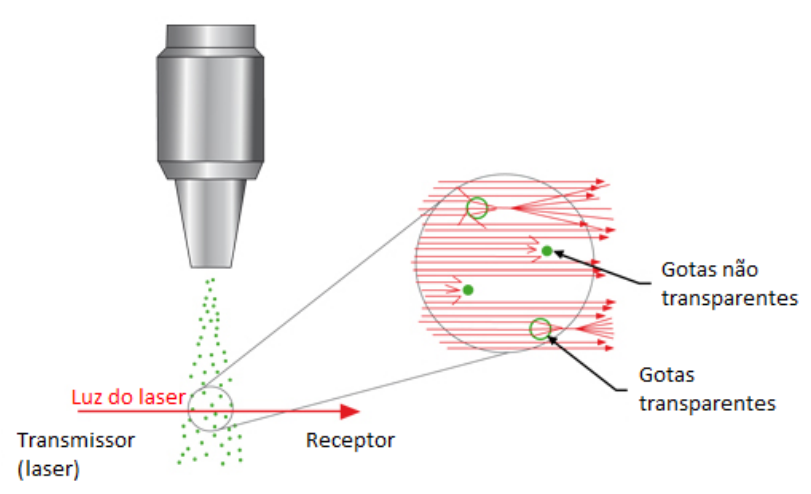

Figura 4: Esquema de um sensor laser Fonte: Adaptado de Sensor Instruments

Ao aplicar o laser no jato de agrotóxicos, parte 
da luz emitida é refratada, refletida e/ou absorvida pelas gotas. A leitura deste sinal gera uma onda que pode ser analisada a fim de se extrair os atributos desejados do leque em questão. A Figura 5 apresenta o gráfico do sinal de um sensor laser com jato ligado e desligado.

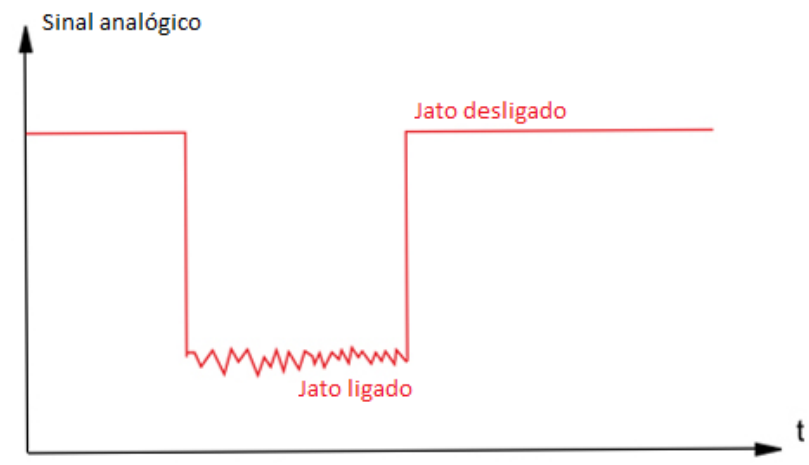

Figura 5: Sinal recebido de um sensor laser com jato ligado e desligado

Fonte: Adaptado de Sensor Instruments

\subsection{Transformada de Fourier}

Joseph Fourier deixou uma grande contribuição para a matemática. A transformada que leva o seu nome é amplamente utilizada em diversas áreas da ciência e tecnologia hoje em dia. A Série de Fourier é uma representação de uma função como uma soma infinita de funções senoidais.

Conforme discutido em Santos (2004), dada uma função $\mathrm{f}$ definida no domínio do tempo, existe uma representação em soma de senos e cossenos com a mesma forma, conforme a equação:

$$
f(x)=\frac{a_{0}}{2}+\sum_{n=1}^{\infty} a_{n} \cos \frac{2 n \pi x}{T}+b_{n} \sin \frac{2 n \pi x}{T}
$$

Na fórmula da Transformada de Fourier, os coeficientes $a_{0}, a_{n}$ e $b_{n}$ são denominados coeficientes de Fourier e T é o período fundamental da função. Através da fórmula de Euler, a equação pode ser escrita na forma de exponencial complexa:

$$
f(x)=\sum_{n \in \mathbb{Z}} c_{n} e^{i \frac{2 \pi}{T} x}
$$

Os coeficientes da forma exponencial da Transformada de Fourier são dados por:

$$
c_{n}=\frac{1}{T} \int_{T} f(x) e^{-i n \frac{2 \Pi}{T} x}
$$

Com a transformada de Fourier na forma de exponencial complexa, é possível traçar um espectro de amplitudes, que representa as amplitudes de cada termo da série. O espectro de amplitudes é tido como uma função de amplitudes por múltiplos de frequência angular, sendo na forma $\left|c_{n}\right| \times n \omega_{0}$, com $n \omega_{0}$ sendo um múltiplo da frequência angular fundamental.

Assim, com este espectro, é possível encontrar a contribuição de cada múltiplo de frequência angular para uma dada função descrita na forma de Fourier.

\subsubsection{Transformada Discreta de Fourier}

Conforme discutido em Joaquim (2010), dada uma sequência de duração finita, a Transformada Discreta de Fourier fornece sua representação no domínio da frequência. Admitindo um sinal discreto no tempo $\mathrm{x}(\mathrm{n})$, com duração finita igual a $\mathrm{N}$, a transformada é dada pela seguinte equação:

$$
X(k)=\sum_{n=0}^{N-1} x(n) W_{N}^{n k}, W_{N}=e^{-j \frac{2 \Pi}{N}}
$$

Pela equação, a sequência $\mathrm{x}(\mathrm{n})$ no domínio do tempo é transformada em uma nova sequência $\mathrm{X}(\mathrm{k})$, com $k$ variando de 1 até $\mathrm{N}-1$, que representa as frequências discretas $w_{k}=\frac{2 \Pi}{N} k$.

Segundo Joaquim (2010), a Transformada Discreta de Fourier permite o cálculo dos espectros de amplitude e de fase a partir de dados discretos de duração finita, sem a necessidade de uma expressão analítica. Dessa maneira, ela consiste em uma ferramenta muito útil em aplicações práticas nas quais se tem um sinal proveniente de algum fenômeno físico ou biológico. Tais sinais são convertidos de contínuos para discretos por um conversor analógico digital, armazenados em um computador e em seguida processados por algoritmos de Transformada Discreta de Fourier, como a FFT.

\subsection{Redes Neurais Artificiais}

De acordo com Haykin (2001), uma Rede Neural Artificial (RNA) é um processador paralelamente distribuído, composto por unidades de processamento que armazenam conhecimento experimental e os tornam disponíveis para uso. Tal rede se assemelha ao cérebro em relação ao conhecimento adquirido, que é baseado em um processo de aprendizagem e pela existência dos pesos sinápticos, que são responsáveis por armazenar os conhecimentos adquiridos.

Ainda segundo Haykin (2001), o processo utilizado para aprendizagem é chamado de algoritmo de aprendizagem, em que são modificados os pesos sinápticos da rede de uma forma ordenada a fim de se obter um resultado esperado.

A RNA é uma técnica computacional, inspirada no funcionamento de neurônios biológicos, que é utilizada para resolução de problemas computacionais de várias naturezas, como classificação, regressão e previsão. Segundo Barreto (2002), as RNAs podem ser consideradas como uma metodologia de resolver problemas característicos da Inteligência Artificial.

Existem vários tipos diferentes de redes neurais artificiais. Um desses tipos é a rede Perceptron, cuja primeira menção foi feita por Rosenblatt (1958) e sua configuração é a mais simples de implementação em uma RNA, devido ao fato de possuir apenas um único 
neurônio. A Figura 6 apresenta o modelo de uma Perceptron.

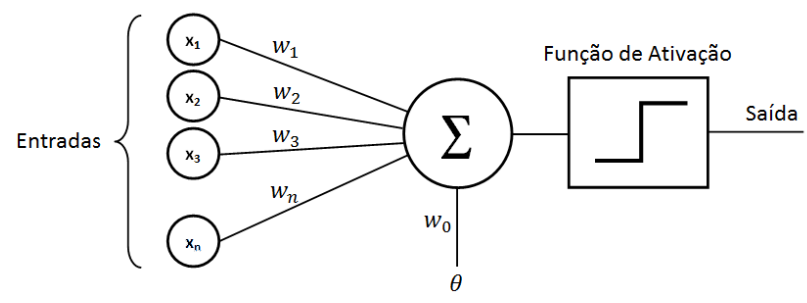

Figura 6: Perceptron

Fonte: Adaptado de Wikimedia

Em seu funcionamento, o neurônio recebe as entradas $\mathrm{x}$, que são multiplicadas por pesos $\mathrm{w}$ e então são somadas. Além das entradas, existe um valor padrão de deslocamento, denominado bias $(\theta)$, que também possui um peso associado e entra no somatório do neurônio. Em seguida, o resultado da soma passa por uma função de ativação, que fornece um resultado de acordo com o valor de entrada.

A Perceptron de Múltiplas Camadas é uma evolução da Perceptron que é caracterizada por possuir uma ou mais camadas intermediárias, localizadas entre as camadas de entrada e de saída da rede. A Figura 7 apresenta um modelo de uma MLP.

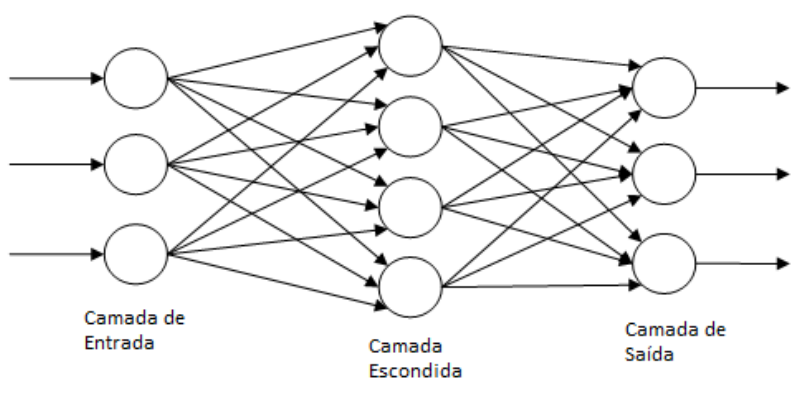

Figura 7: Modelo geral de uma MLP Fonte: Adaptado de Research Gate

Segundo Haykin (2001), o treinamento de uma RNA consiste no ajuste dos pesos visando determinado comportamento para um conjunto de dados de entrada. $\mathrm{O}$ algoritmo de treinamento Backpropagation realiza o treinamento da rede nas seguintes etapas: Primeiramente, em uma etapa denominada forward, um conjunto de valores é inserido na rede e passa pelas camadas até a geração de uma saída. Em seguida, este resultado é comparado com a saída desejada, gerando um valor de diferença, ou erro. Assim, em uma próxima etapa, denominada backward, esta diferença entre valor esperado e valor obtido é propagada no sentido inverso da rede, onde os valores dos pesos são ajustados. Esse processo então é repetido para cada conjunto de dados a serem representados pela rede, a fim de gerar novos ajustes até chegar a um modelo satisfatório.

\subsection{Microcontroladores e Circuitos}

\subsubsection{Plataforma de Prototipagem Arduíno}

Um microcontrolador é um dispositivo utilizado para aplicações específicas. Possui um núcleo de processamento, memória e periféricos de entrada e saída que compõem um computador básico.

Segundo McRoberts (2011), o Arduíno é um pequeno computador programável que pode processar entradas e saídas entre ele e componentes externos conectados a ele. Consiste em uma plataforma de computação física ou embarcada, isto é, um sistema que é capaz de interagir com um ambiente externo através do uso de hardware e software. A Figura 8 apresenta o modelo de placa Arduíno Uno, que possui um microcontrolador.

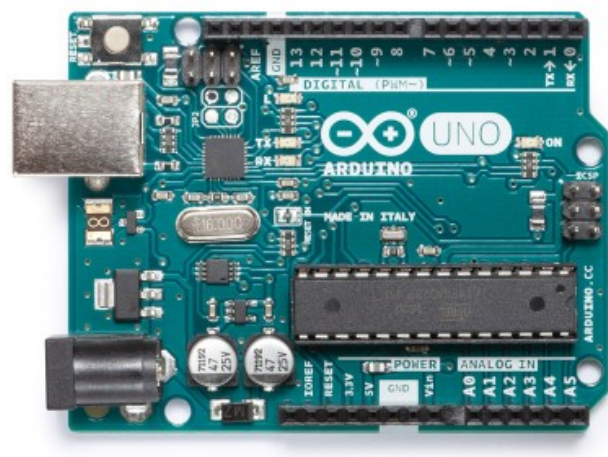

Figura 8: Arduíno Uno Fonte: Arduino Store

As portas do Arduíno podem ser classificadas como analógicas ou digitais. As portas analógicas possuem conversores de sinal analógico para digital e digital para analógico. A resolução padrão é de 10 bits, isto é, o sinal de oV a 5V pode ser mapeado em 1024 valores inteiros. Já as portas digitais trabalham com dois estados, sendo estes o alto (5V) e o baixo (oV).

Algumas portas digitais permitem a utilização da modulação por largura de pulso (PWM). Dado um período de tempo T constante do sinal, o PWM define qual o percentual de T o sinal fica alto ou baixo. Uma aplicação prática dessa função é o controle de potência de dispositivos, através da geração de uma tensão média com base na largura dos pulsos. A Figura 9 demonstra um exemplo de onda com PWM. Dado um sinal de $12 \mathrm{~V}$, em um período de $50 \mu \mathrm{s}$, a modulação faz com que em $80 \%$ do período ( $40 \mu \mathrm{s}$ ) o sinal fique alto e o restante do período fique baixo. Assim, têm-se uma tensão média de $9.6 \mathrm{~V}$.

\subsubsection{Circuitos de Filtro de Sinais}

De acordo com Boylestad (2012), toda combinação de dispositivos passivos (resistores, indutores ou capacitores) ou ativos (transistores e amplificadores operacionais) empregados em um projeto de circuito para selecionar uma faixa de frequência específica é chamado de filtro. Os filtros possuem aplicações em comunicação, sistemas de som e remoção de frequências indesejáveis, denominadas ruídos.

Os filtros eletrônicos podem ser classificados 


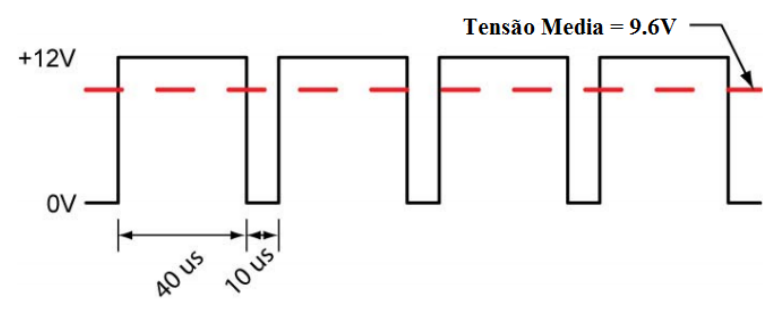

Figura 9: Exemplo de PWM, com largura de pulso de $80 \%$ do período total

Fonte: MecaWeb

quanto à tecnologia e à função. No que diz respeito à tecnologia, podem ser:

- Passivos: construídos com base em combinações de resistores, capacitores e indutores.

- Ativos: além dos componentes presentes em filtros passivos, utilizam também transistores, válvulas e amplificadores operacionais.

Quanto às funções, os filtros de sinais podem ser classificados como passa-baixa, passa-alta, passafaixa e rejeita-faixa.

Os filtros elétricos com a função de passa-baixa têm a característica de permitir a passagem de frequências abaixo de uma dada frequência e atenuar as frequências que estão acima desta. Tal frequência limiar é conhecida como frequência de corte $\left(f_{c}\right)$. A Figura 10 apresenta o circuito do filtro passa-baixas.

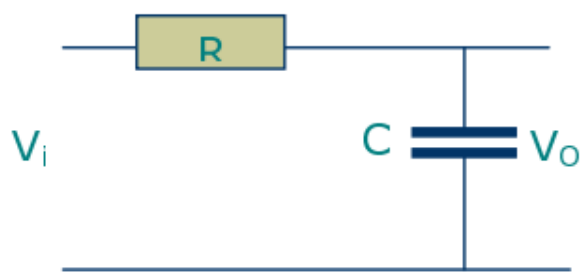

Figura 10: Filtro R-C passa-baixas Fonte: Onuki (2005)

O circuito consiste em um resistor (R) e um capacitor (C). Em seu funcionamente, um sinal de entrada $\left(V_{i}\right)$ passa pelo circuito que então gera um sinal de saída $\left(V_{0}\right)$.

Na operação de um filtro, existem três bandas distintas: banda de passagem, banda de transição e banda de corte. A banda de passagem é a banda cujo filtro permite a passagem; a banda de corte é a banda atenuada e a banda de transição é a transição entre passagem e corte. A Figura 11 mostra o gráfico de atuação do filtro passa-baixas.

$O$ cálculo da frequência de corte para o filtro passabaixas é dado por:

$$
f_{c}=\frac{1}{2 \Pi R C}
$$

Já o filtro passa-altas possui a característica de permitir a passagem de frequências acima de uma dada frequência de corte e atenuar outras

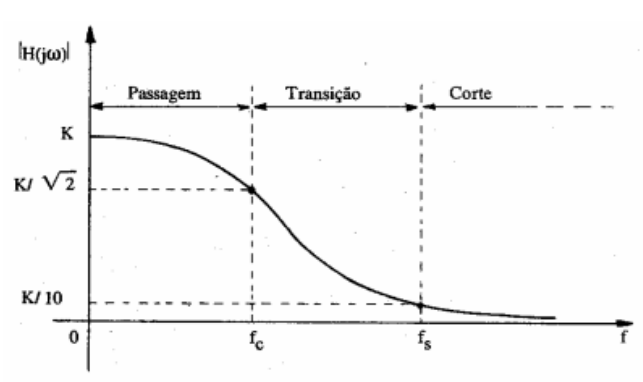

Figura 11: Distribuição de frequências de um sinal sob um filtro passa-baixas

Fonte: Onuki (2005)

frequências abaixo do limiar estabelecido. Os filtros passa-faixas e rejeita-faixas são combinações de filtros passa-baixas e passa-altas e suas funções são, respectivamente, permitir e atenuar uma determinada faixa de valores de frequência.

\subsubsection{Circuitos Amplificadores}

De acordo com Boylestad and Nashelsky (2013), um amplificador operacional é um amplificador diferencial de alto ganho, com alta impedância de entrada e baixa impedância de saída. Dentre as aplicações típicas dos amplificadores operacionais estão as de alterações de valores de tensão, osciladores, filtros e diversos tipos de circuitos de instrumentação. A Figura 12 mostra a simbologia utilizada na representação de um amplificador operacional.

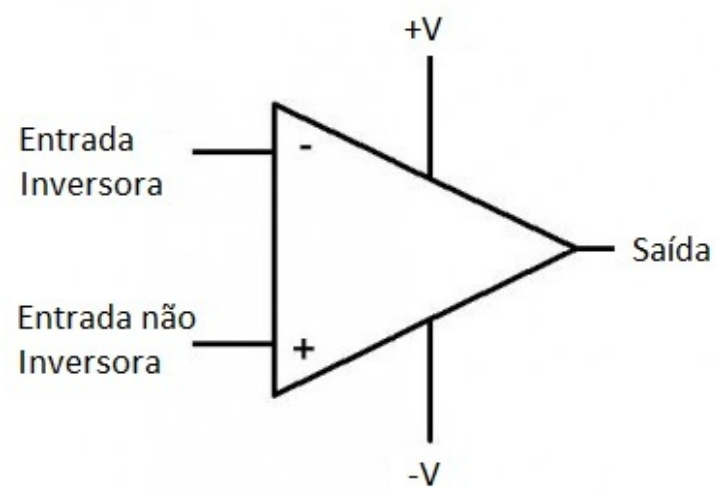

Figura 12: Simbologia e terminais de um amplificador operacional

Existem várias configurações para a utilização de um amplificador operacional, sendo cada uma responsável por um comportamento específico, de acordo com a necessidade. Uma configuração muito utilizada para amplificação de sinais é a configuração de amplificador inversor. Conforme explicado por Boylestad and Nashelsky (2013), esta configuração define um ganho constante aplicado ao sinal de entrada. A Figura 13 mostra a configuração de amplificador inversor.

Nesta configuração, a saída é invertida em relação a entrada. O ganho é obtido através dos valores utilizados nos resistores de entrada e de 


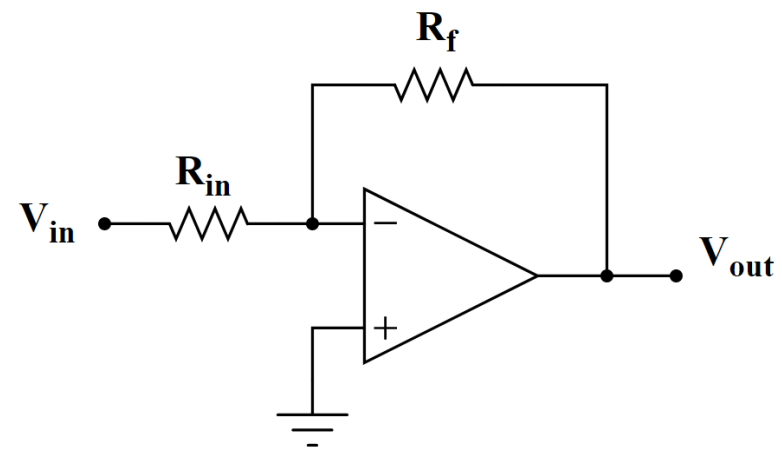

Figura 13: Configuração de amplificador inversor Fonte: Boylestad and Nashelsky (2013)

realimentação. A equação a seguir rege o ganho determinado pela configuração.

$$
V_{\text {out }}=-\frac{R_{f}}{R_{\text {in }}} \cdot V_{\text {in }}
$$

sendo $V_{\text {out }}$ a tensão de saída, $V_{\text {in }}$ a tensão de entrada, $R_{f}$ e $R_{\text {in }}$ as resistências de realimentação e de entrada, respectivamente.

\section{Metodologia}

Para a realização do presente trabalho, o primeiro passo foi o projeto e a construção da bancada de testes, necessária para realização das simulações e posterior captura de dados para análise.

Em seguida, foi construído um sistema para tratamento e aquisição dos sinais do raio laser para posterior processamento. Foi utilizado um circuito analógico para processamento do sinal em tempo contínuo e foi utilizado um microcontrolador Arduíno para aquisição dos dados. Além disso, foi criado um programa de computador para visualização em tempo real dos dados recebidos pelo Arduíno.

Após a construção do circuito, foi realizada uma amostragem de valores para criação do classificador. Assim, foi desenvolvido um classificador, pelo qual foram obtidos os resultados finais deste trabalho.

As etapas são descritas nos tópicos a seguir.

\subsection{Bancada de Testes}

Para construção da bancada, foram utilizados os seguintes materiais:

- Chapa de Aço Inox

- Placa de Acrílico.

- Placas de MDF.

- Cano PVC 1/2 polegada.

- Mangueira.

- Válvula seletora de pontas de pulverização hidráulica.

- Perfil de Metal.

- Ponta de pulverização AI11002-VS.

- Ponta de pulverização 11002-BD.

- Módulo Laser Arduíno K-008.

- Fototransistor.
Grande parte dos materiais utilizados na construção da bancada foram reaproveitados, sendo exceções a válvula e as pontas, que foram concedidas pelo departamento para realização dos experimentos. A bancada foi projetada para realização dos experimentos utilizando-se água como fluido de teste. A Figura 14 apresenta o esquema da montagem da bancada desenvolvida.

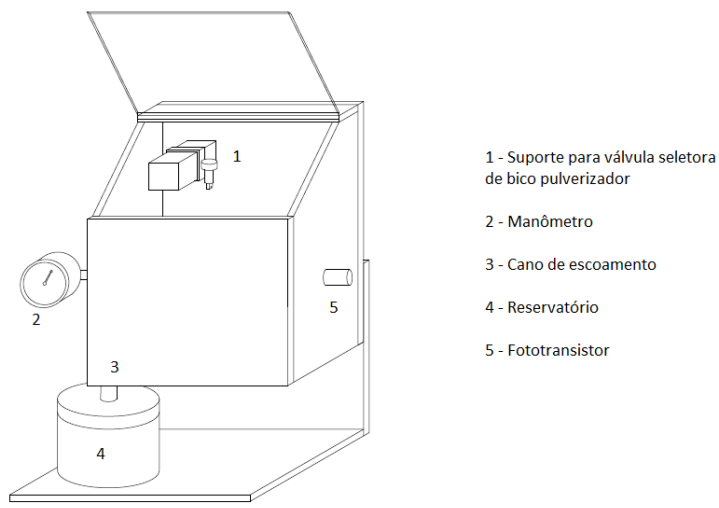

Figura 14: Projeto da bancada de testes

O sistema foi projetado para se comportar como um circuito fechado de água, utilizando uma bomba hidráulica para alimentação. A entrada de água no sistema ocorre pela válvula seletora de pontas de pulverização, que é alimentada por uma mangueira ligada à bomba. A saída de água ocorre pelo cano de escoamento, onde segue para o recipiente sobre o qual a bomba opera e então é novamente bombeada para a ponta de pulverização.

Um problema em relação a disposição do emissor laser e fototransistor foi a deposição de água na frente dos sensores, o que poderia comprometer tanto a emissão quanto a recepção do sinal. Para evitar tal problema, a acoplagem desses componentes foi feita utilizando cano PVC com uma leve inclinação para a ocorrência do escoamento das gotas depositadas na região. A Figura 15 mostra um esboço da proteção desenvolvida.

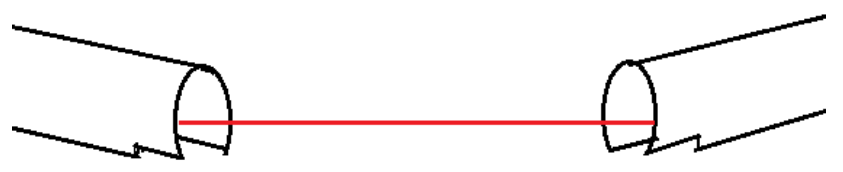

Figura 15: Inclinação do acoplamento do sensor laser e fototransistor

O sistema foi construído utilizando como base placas de MDF. No fundo do tanque, foi utilizada uma chapa de aço inox. O vedamento das ligações foi feito com veda calha. Visando o vedamento e a proteção da madeira, o sistema foi pintado com tinta a óleo na cor azul. 
Na válvula seletora de pontas, foram utilizados as pontas de modelos AI11002-VS e 11002-BD, sendo estas das marcas Teejet e Magnojet, respectivamente. O primeiro forma um spray com formato de jato, i.e, gotas maiores. Segundo a fabricante da ponta, as gotas formadas pelo mesmo são da faixa extremamente grossa (XC), com diâmetro médio variando entre 503 e 665 mícrons, sob pressão de 3 bars. Já o segundo, forma um spray em formato de névoa, gotas menores. A faixa especificada pela fabricante para esta ponta é fina $(\mathrm{F})$, com diâmetro médio variando entre 106 e 235 mícrons. As faixas de tamanho de gotas foram definidas na Tabela 1. Esses foram os dois padrões de espectro de gotas utilizados nos experimentos do trabalho. A imagem das pontas é apresentada na Figura 16.

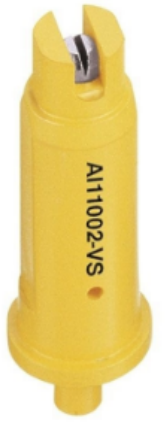

(a)

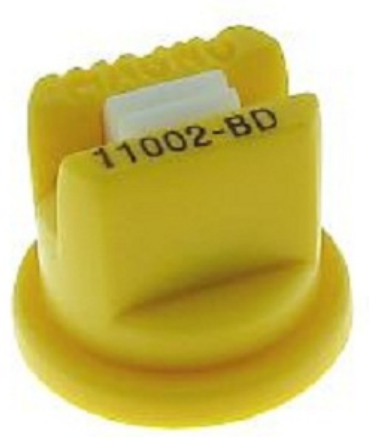

(b)
Figura 16: Pontas de pulverização modelos AI11002-VS (a) e 11002-BD (b)

Fonte: Adaptado de Sidist e Sprayerdepot

Para o funcionamento do sistema, foi utilizado uma bomba hidráulica e um recipiente com água, dispostos na saída de água do tanque. A bomba teve sua potência ajustada para trabalhar com pressão de 3 bars.

\subsection{Sistema de Tratamento e Aquisição de Sinais}

Nesta etapa, foram utilizados os seguintes materiais:

- Amplificador operacional modelo UA741CN.

- Osciloscópio Agilent Technologies modelo DSO-X 2002A.

- Arduíno UNO R3.

- 2 Resistores $330 \Omega$.

- 4 Resistores $1 \mathrm{k} \Omega$.

- 1 Resistor $10 \mathrm{k} \Omega$.

- 1 Resistor $20 \mathrm{k} \Omega$.

- 2 Capacitores 10nF.

- 1 Capacitor 100nF.

- 1 Capacitor $6,8 \mu \mathrm{F}$.

- Placa de fenolite.

- Estanho para soldagem dos componentes na placa.

- Arduíno IDE, Visual Studio e RStudio para desenvolvimento dos programas.

No experimento, quando uma gota intercepta o sinal do laser, parte da luz pode ser refletida, refretada ou absorvida, dependendo do tipo de produto utilizado e do ângulo de incidência da luz na mesma. Assim, muitas gotas presentes no caminho do laser geram um efeito de espalhamento da luz, o que resulta em uma diminuição de intensidade de sinal que atravessa o meio e chega ao fototransistor.

Para a realização dos experimentos, foi utilizado o valor de tensão medido no coletor do fototransistor. Esse sinal apresenta uma variação em decorrência da variação de intensidade de luz recebida na base. Esses valores formam uma onda característica resultante da variação de intensidade do laser que atravessa o leque de gotas formado pela ponta de pulverização.

O sistema de tratamento e aquisição de sinais foi construído para preparar os valores obtidos para posterior processamento através do classificador. Esse sistema foi composto por um circuito de condicionamento de sinais, responsável por condicionar o sinal em um formato para processamento e um software para captura dos sinais, desenvolvido no Arduíno.

\subsubsection{Circuito de Condicionamento de Sinais}

O circuito de condicionamento de sinais foi projetado para fazer com que o sinal recebido do fototransistor passasse por algumas etapas antes de ser, de fato, processado para gerar os dados de análise deste trabalho. As etapas de ajuste do sinal foram feitas através de um circuito analógico. A Figura 17 apresenta um diagrama que representa o fluxo do sinal.

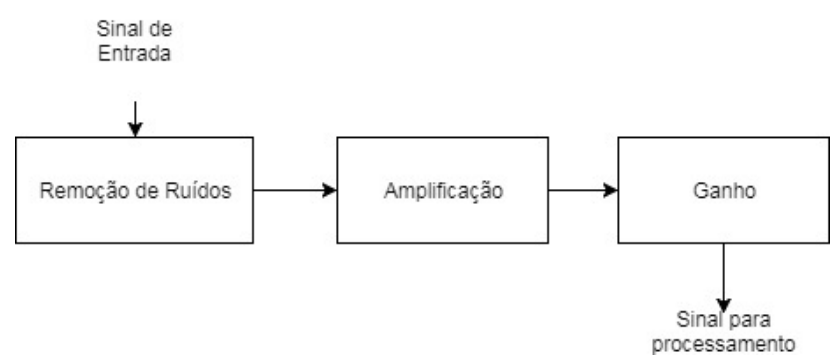

Figura 17: Etapas de ajuste do sinal de entrada para processamento

Para a remoção de ruídos, foram utilizados dois filtros passa-baixas, calculados para passagem de frequências abaixo de $50 \mathrm{kHz}$ de oscilação e um capacitor para minimização da componente contínua do sinal. Esses filtros foram dispostos em série para maximizar o decaimento das frequências indesejáveis.

$\mathrm{Na}$ etapa de amplificação, foi utilizado um amplificador operacional com configuração de amplificação inversora de ganho constante para realização do incremento necessário de amplitude do sinal. O ganho resultante da configuração projetada foi feito em função da amplitude do sinal de entrada, que era de aproximadamente 100 milivolts de pico a pico. Assim, o valor de ganho foi de 20 vezes, elevando assim a amplitude à aproximadamente 2 volts de pico a pico.

Após a amplificação, o sinal apresentou uma forma 


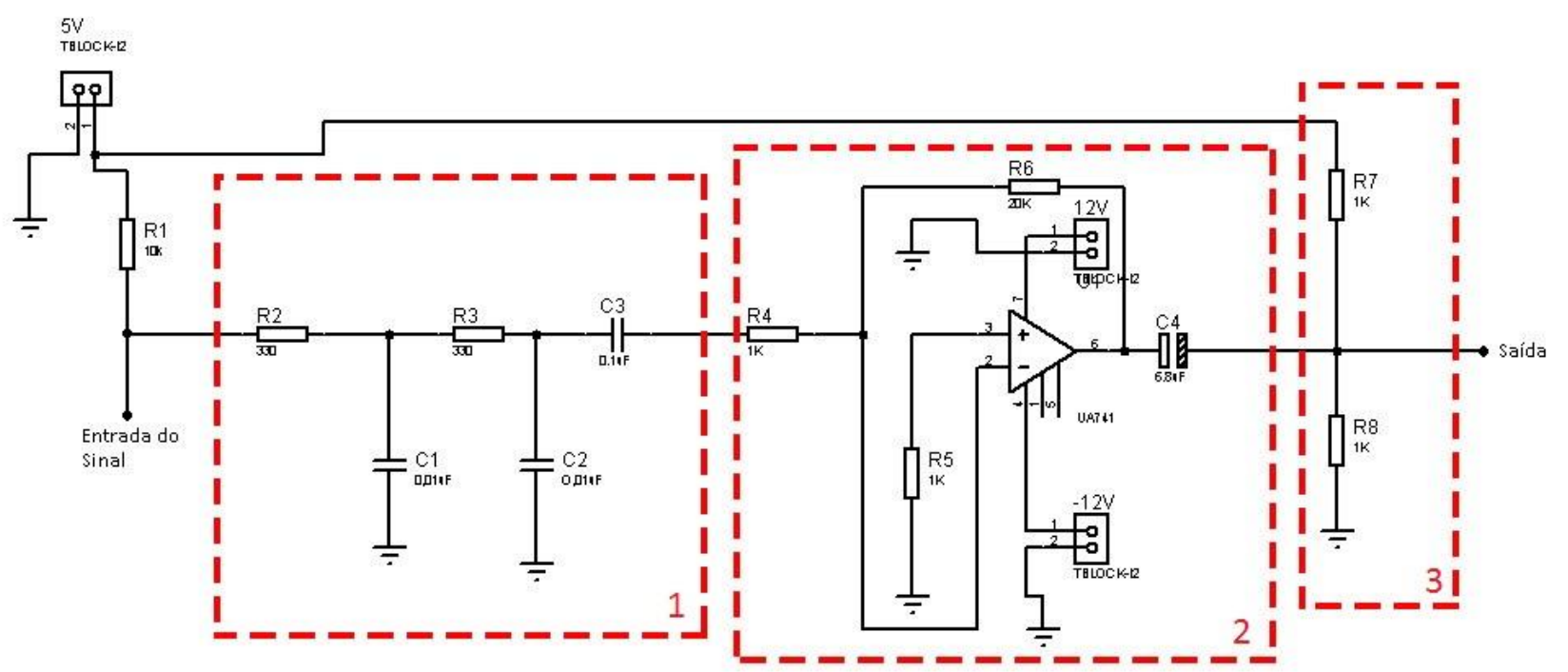

Figura 18: Circuito analógico utilizado para realização das etapas de tratamento do sinal

de tensão alternada. Como o conversor AD da placa digital só suporta valores positivos de tensão, sendo estes de oV a 5V, foi utilizado um divisor de tensão visando acrescer o sinal com um valor de tensão (offset), centrando-se em aproximadamente 2,5V. A Figura 18 apresenta o esquema do circuito construído.

Conforme observado na imagem, os filtros estão presentes na parte delimitada 1 do circuito, o amplificador na região 2 e o divisor de tensão para deslocamento do sinal na região 3. O circuito foi projetado para ser construído em uma placa de fenolite, através do software Proteus 8.5. A Figura 19 apresenta o projeto de trilhas para impressão e confecção da placa.

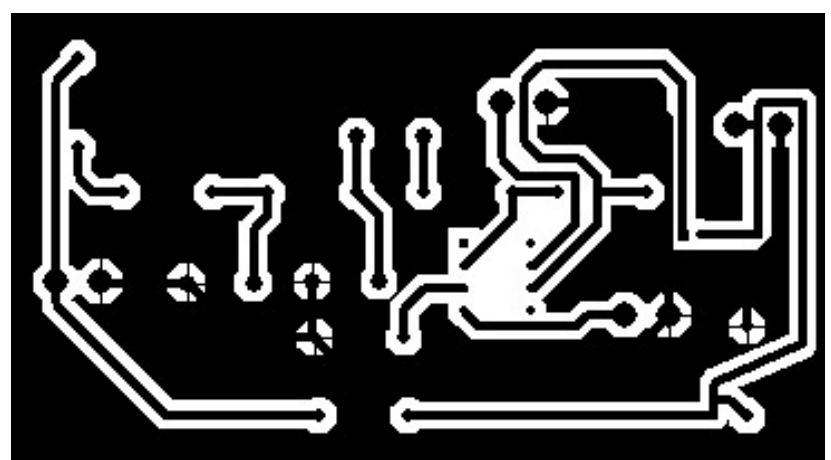

Figura 19: Trilhas do circuito projetado para impressão. Circuito de face simples com dimensões de $20 \mathrm{~cm} \times 10 \mathrm{~cm}$

\subsubsection{Software para Captura dos Sinais}

Com o sinal preparado para processamento, foi desenvolvido um programa para Arduíno para realizar a leitura e calcular os valores de amplitudes do espectro de frequência baseados no algoritmo de transformada rápida de Fourier.

Para o cálculo da série de Fourier do sinal de entrada, foi utilizada uma biblioteca desenvolvida pela Open Music Labs. A rotina foi implementada para ler uma quantidade de 256 valores do sinal de entrada, espaçados igualmente no tempo, realizar as operações da FFT e retornar um conjunto de 128 amplitudes de faixas de frequências. A Figura 20 mostra o fluxo de processos da rotina implementada no Arduíno.

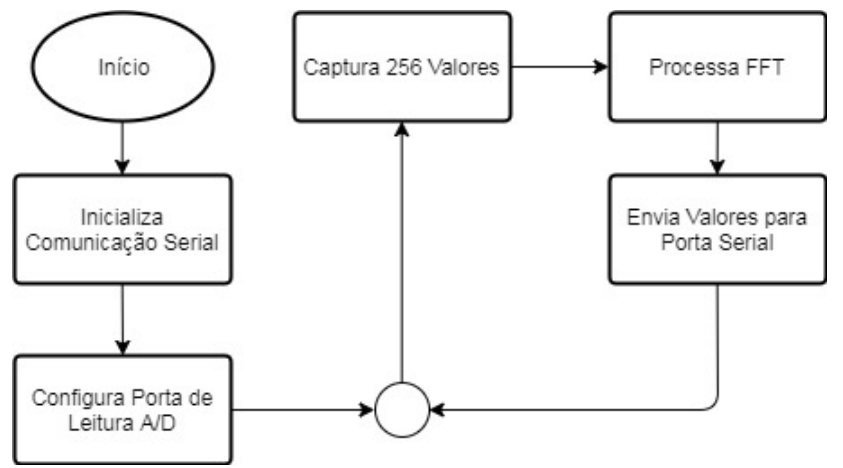

Figura 20: Fluxograma de processos do programa do Arduíno

Para realização dos testes da rotina, foi utilizado um gerador de sinal para gerar ondas de diferentes frequências. Assim, esses sinais foram analisados pelos valores processados no Arduíno para verificar o comportamento dos espectros gerados. Com isso, observou-se que para as frequências geradas, os picos de frequência no espectro eram bem definidos.

Além do programa do Arduíno, foi desenvolvido um programa de computador, em linguagem C\#, para geração de gráficos em tempo real dos valores processados no Arduíno. Basicamente, o programa fazia a leitura de um conjunto de valores processados via comunicação serial com a placa Arduíno e então mostrava em um gráfico. Essa aplicação foi utilizada para analisar visualmente os gráficos de FFT obtidos. A Figura 21 apresenta o diagrama de casos de uso da aplicação. 


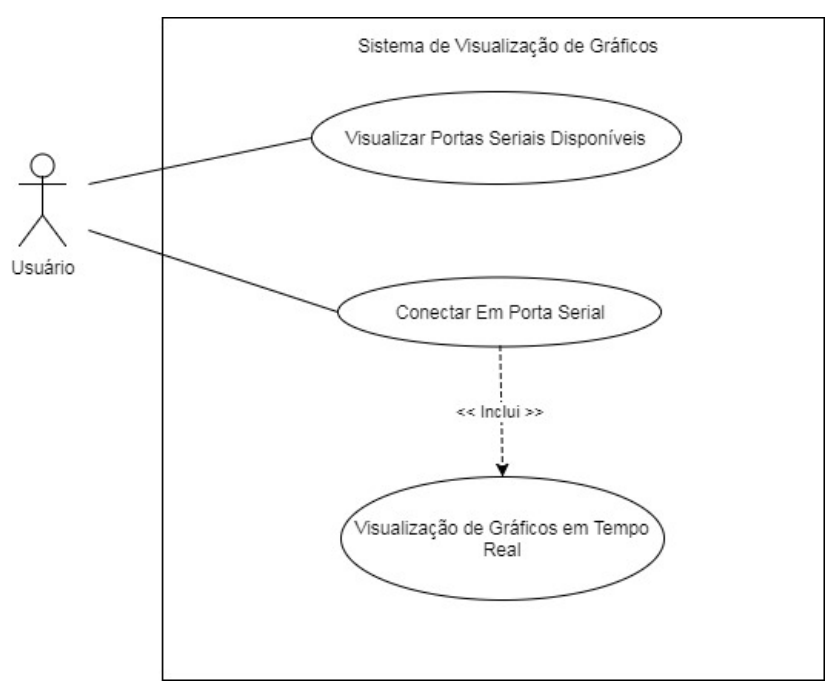

Figura 21: Diagrama de casos de uso da aplicação de visualização de gráficos

\subsection{Classificação}

No desenvolvimento do programa classificador de espectros de gotas, foi utilizada a linguagem de programação R, com o pacote RSNNS. A técnica de classificação adotada foi a utilização de uma RNA do tipo MLP.

Antes da classificação, foi realizada a coleta dos dados. Foram capturados 300 espectros para cada ponta de pulverização utilizada. Como as amplitudes da série de Fourier apresentaram pequenas variações, foi utilizado uma média de 3, tendo-se, portanto, a criação de um conjunto de dados com 200 espectros médios, sendo 100 de cada tipo. A média aritmética foi utilizada para suavizar as diferenças dos sinais instantâneos, comportando-se como um filtro matemático passa-baixas. Além da média, esses valores foram padronizados e mapeados para valores entre 0 e 1 para realização do treinamento da rede.

Os parâmetros da arquitetura da MLP utilizada podem ser apreciados na Tabela 2.

Tabela 2: Parâmetros utilizados na MLP

\begin{tabular}{lc}
\hline Atributo & Valor \\
\hline $\begin{array}{c}\text { Quantidade de Camadas } \\
\text { Escondidas }\end{array}$ & 1 \\
$\begin{array}{c}\text { Número de Neurônios na } \\
\text { Camada Escondida }\end{array}$ & 15 \\
Pesos Iniciais & Aleatórios entre -0,3 e 0,3 \\
Função de Ativação & Função Logística \\
Neurônios Escondidos & Backpropagation \\
Algoritmo de Aprendizado & 0,02 \\
Taxa de Aprendizagem & Linear \\
Função de saída & 3000 \\
Máximo de Épocas &
\end{tabular}

Os dados foram divididos em cinco grupos de igual tamanho. Para obtenção da acurácia do classificador, foi feita uma validação cruzada utilizando-se o método de $k$-fold: foi feito um rodízio entre o grupo de treinamento e o grupo de validação, sendo estes $80 \%$ e $20 \%$ do dataset total, respectivamente.

A partir dos conjuntos de dados, foram derivados cinco modelos de classificação. Cada modelo consiste em uma rede do tipo MLP e é treinado com um subconjunto dos dados. Assim, é possível avaliar a capacidade de aprendizado do modelo em relação a natureza dos dados trabalhados e a representatividade de cada subconjunto de treinamento em relação ao conjunto total amostrado. Cada MLP foi treinada utilizando o algoritmo backpropagation. Com a validação cruzada, foi possível chegar aos valores de erros apresentados por cada modelo e à acurácia geral do método proposto.

\section{Resultados e Discussão}

Com a construção da bancada de testes, foi possível realizar a simulação do ambiente de pulverização. Na Figura 22 é apresentada uma imagem da bancada experimental construída.

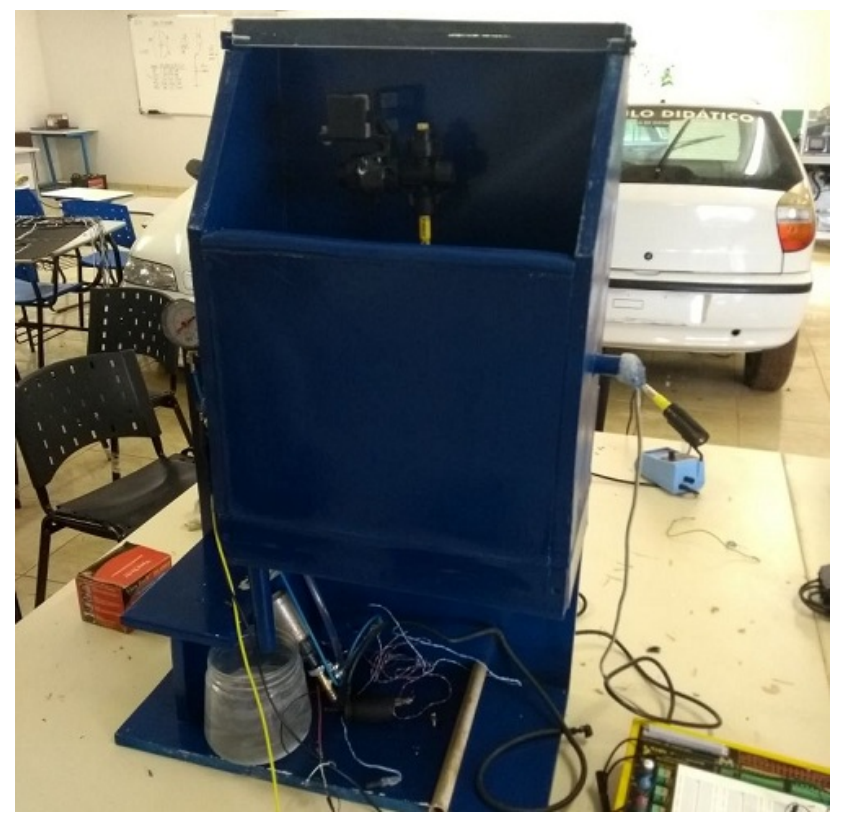

Figura 22: Bancada de testes

A etapa de construção da bancada apresentou algumas dificuldades. $\mathrm{O}$ vedamento inicial não funcionou como esperado, ocasionando vasamentos e inchamento de parte da madeira, consequente da água infiltrada. Assim, o vedamento das ligações de madeira foi reforçado, corrigindo o problema. O alinhamento do emissor e receptor laser sofreu algumas alterações em decorrência de movimentações e do deslocamento da madeira devido ao inchamento. Como o acoplamento do fototransistor foi fixado de forma a permitir ajuste, o alinhamento pôde ser corrigido.

Para a realização dos experimentos na bancada de testes, a potência da bomba hidráulica foi ajustada para obtenção do valor de pressão de trabalho de 300 $\mathrm{kPa}$. Este ajuste foi realizado através de um circuito controlador de potência via PWM. 
Inicialmente, foi construído um circuito sem filtros de frequência para capturar o sinal e analisar no osciloscópio. Assim, foi observado que a variação dos espectros estava abaixo de $50 \mathrm{kHz}$. Dessa maneira, foram definidos os filtros passa-baixas utilizados no projeto do circuito final. Com isso, a placa final para condicionamento dos sinais foi construída, conforme apreciado na Figura 23.

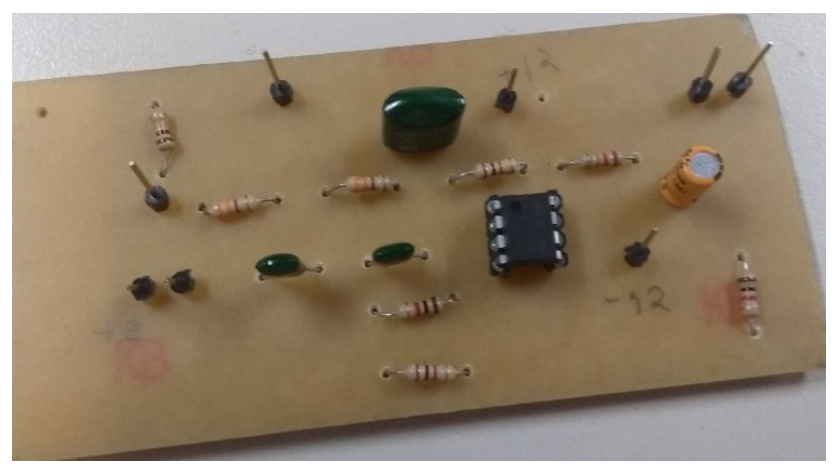

Figura 23: Placa de condicionamento de sinais

Através das análises com o osciloscópio, cujos gráficos são apresentados na Figura 24, foi observado que espectros de gotas com gotas pequenas, gerados pela ponta $11002-\mathrm{BD}$, apresentaram, no espectro de amplitudes de Fourier, contribuições mais baixas nas frequências menores e uma distribuição mais suave ao longo do espectro. Este padrão apresentou uma concentração de frequências visivelmente na região do espectro que vai até $20 \mathrm{kHz}$. Já os espectros com gotas maiores, geradas pela ponta AI11002VS, apresentaram altos picos de contribuição em frequências mais baixas e uma queda de contribuição mais rápida com o aumento das frequências, formando uma concentração visível de frequências na região do espectro até a escala de $15 \mathrm{kHz}$. Dessa forma, foi possível diferenciar visualmente os dois espectros trabalhados.

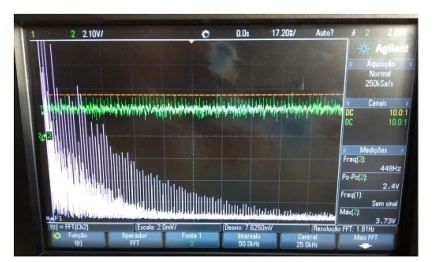

(a)

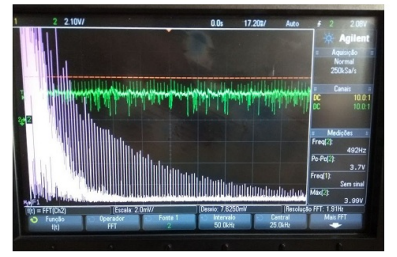

(b)
Figura 24: Sinais capturados (em verde) e espectros de Fourier (em roxo) das pontas trabalhadas por meio do osciloscópio para os padrões de névoa (a) e jato (b)

Assim como Rufino (2011) demonstrou em seu trabalho que o fenômeno espalhamento da luz em decorrência de partículas sobre sua trajetória pode ser utilizado para medir, detectar e controlar a concentração de partículas suspensa no ar, também foi observado que o mesmo efeito pode ser utilizado para a extração de informações de um spray de agentes químicos no ato da pulverização. No método utilizado por Rufino (2011), o sinal foi analisado com base na amplitude. O objetivo era verificar a quantidade de partículas suspensas no ar, sem discernir o padrão dos espectros. Neste trabalho, contudo, foi possível observar em testes que a amplitude pode ser suscetível a erros, como sujeira na lente do laser e foto transistor, interferências e impedância dos cabos e conexões. Outro problema em relação à amplitude, descrito por Rufino (2011), foi alteração da intensidade dos valores de leitura em decorrência da variação de taxa de absorção de luz para partículas de cores diferentes. Foi observado nos testes que a distribuição de frequências apresentava o mesmo comportamento, independente da amplitude do sinal.

Após a construção do sistema de aquisição de dados, foram obtidos os gráficos de série de Fourier através dos software de visualização de gráficos desenvolvido. A Figura 25 apresenta a interface da aplicação em questão.

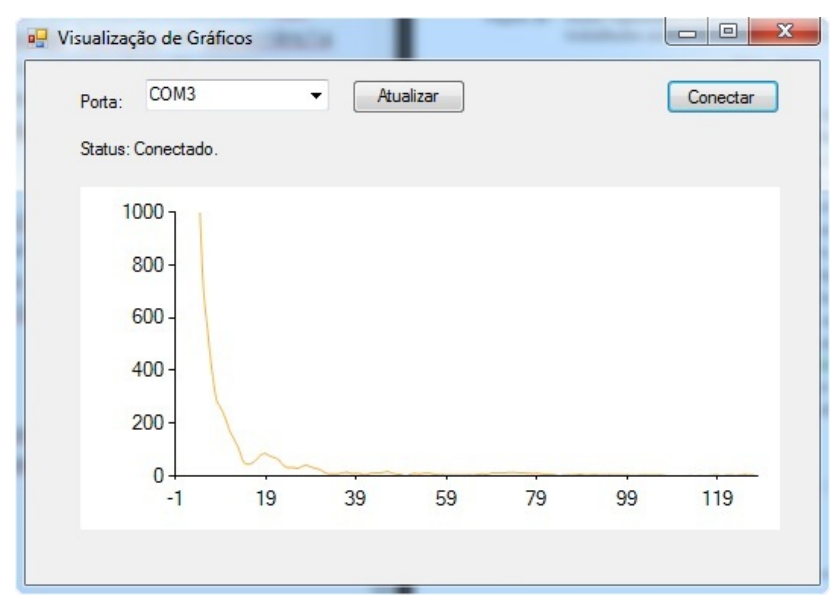

Figura 25: Interface do sistema desenvolvido

Através dos dados coletados, foi observado visualmente que o microcontrolador foi capaz de detectar os diferentes espectros, conforme apresentado na Figura 26.
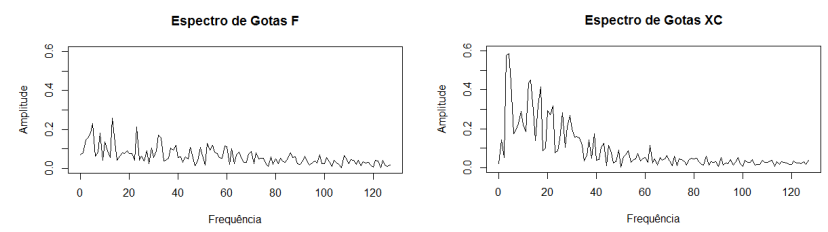

Figura 26: Espectros de Fourier obtidos pelo Arduíno para os padrões de gotas finas e extremamente grossas

Além da comparação entre os padrões, foi feito um teste para medir a quantidade de ruídos presentes no sinal. Para tal, foi feita uma obstrução da passagem de luz do laser para o fototransistor a fim de observar o sinal residual. Assim, foi observado que, com a ausência de sinal, o espectro era aproximadamente nulo, o que levou a conclusão de 
que as frequências observadas no sinal apresentavam baixas contribuições de ruídos.

Para a criação da RNA classificadora, foram utilizados 160 valores médios de espectros de amplitude de Fourier para realização do treinamento e 40 valores médios para validação, fazendo-se uma rotação do conjunto de validação para obtenção do erro médio. A Tabela 3 apresenta os erros obtidos em cada modelo treinado.

Tabela 3: Erro apresentado nos modelos treinados

\begin{tabular}{lccc}
\hline Modelo & Erro Quadrático Médio & Erros & Acurácia \\
\hline Modelo 1 & 0.13396 & 6 & $85 \%$ \\
Modelo 2 & 0.09792 & 4 & $90 \%$ \\
Modelo 3 & 0.10714 & 3 & $92.5 \%$ \\
Modelo 4 & 0.08188 & 2 & $95 \%$ \\
Modelo 5 & 0.16908 & 3 & $92.5 \%$ \\
\hline
\end{tabular}

Como a função de saída da rede foi definida como função identidade, a resposta a uma entrada era dada em valores decimais. Assim, para calcular os erros quadráticos médios, esses valores foram comparados com os valores esperados, sendo o para gotas finas e 1 para gotas grossas.

O valor decimal fornecido pela rede diz respeito ao quão determinado espectro de frequências se aproxima do padrão de gotas finas e de gotas grossas. Dessa forma, o classificador se baseia em qual padrão fica mais próximo, como uma função degrau, para fornecer o resultado.

As acurácias foram calculadas com base no percentual de acerto para cada modelo treinado. Para cálculo da acurácia do método proposto, foi utilizada a média das acurácias obtidas em cada um dos modelos treinados. $\mathrm{O}$ método apresentou acurácia média de $91 \%$ na identificação de espectros de gotas finas e extremamente grossas baseado nas amplitudes das componentes de frequência.

Neste trabalho, foram analisados duas pontas de pulverização cujo espaçamento entre os valores de diâmetro das gotas geradas era grande. Inicialmente, esses bicos foram escolhidos em decorrência do caráter investigativo do trabalho: entender a relação entre as componentes de frequências presentes no sinal de laser obtido e o diâmebro médio das gotas geradas pelo processo de pulverização. Tendo isso em vista, foi possível verificar as diferenças nos espectros e concluir que as frequências variam com o tamanho das gotas, apresentando um comportamento definido para cada tamanho.

A partir dos resultados obtidos, novos estudos podem ser traçados no âmbito de identificação de espectros de gotas através do uso do sensoriamento laser. Espera-se a utilização de não apenas duas pontas, mas várias, com pressões de trabalho diferentes, leques diferentes e tamanhos diferentes. Também podem ser feitos testes com ângulos diferentes e, além disso, utilizar mais de um raio laser a interceptar o leque. Com isso, seria possível analisar o comportamento das frequências em função de uma grande quantidade de variáveis.

Caso esses dados apresentem uma correlação com as pontas, os tamanhos de gotas gerados, a pressão de trabalho e a vazão, seria possível criar um regressor para identificar espectros de gotas com diferentes valores de diâmetro. A partir disso, seria possível criar soluções acessíveis para o produtor verificar, em tempo real, o espectro de gotas corrente no ato da pulverização, o que consiste no objetivo final deste estudo.

\section{Conclusões}

A bancada de testes desenvolvida permitiu a realização das simulações de pulverização para coleta e análise de dados previstos nos objetivos do trabalho. Esta bancada poderá ser utilizada para a avaliação de novas abordagens em estudos futuros, como análise de dados para diferentes pontas de pulverização, sob diferentes pressões de trabalho.

O software desenvolvido para o Arduíno permitiu a extração dos espectros de frequências dos sinais captados pelo sensor laser, permitindo, assim, a análise dos dados no domínio da frequência. Além disso, foi possível observar visualmente o comportamento desses espectros através do software de visualização de gráficos desenvolvido. Quanto maiores as gotas interceptando o feixe de luz do laser, maiores são as componentes de baixa frequência presentes no sinal.

Com a acurácia do método na identificação dos espectros de gotas trabalhados, foi possível observar que a classificação dos padrões de pulverização pode ser realizada através de sensoriamento laser utilizando a técnica de tratamento de transformada rápida de Fourier. A metodologia proposta neste trabalho é passível de aprimoramento em vários aspectos para realização das classificações, tais como no circuito de aquisição de dados, na quantidade de raios laser utilizados, nas técnicas de tratamento de dados e no algoritmo de classificação. Além disso, para aprimorar a análise dos dados, pode ser empregado nos testes a variação dos valores de pressão de trabalho e da direção dos leques gerados.

Acredita-se que o modelo proposto possa gerar um regressor para detecção do diâmetro das gotas das pontas de pulverização hidráulica utilizadas na pulverização. Assim, este trabalho é ponto de partida para novos estudos, visando a criação de um sensor de baixo custo que possibilitará aos agricultores monitorarem o espectro de gotas de aplicação dos agentes químicos em tempo real, evitando os problemas de uma aplicação inadequada.

\section{Referências}

Barreto, J. M. (2002). Introdução às redes neurais artificiais, Florianópolis: UFSC .

Boylestad, R. L. (2012). Introdução à Análise de Circuitos, 12 edn, Pearson Prentice Hall, São Paulo.

Boylestad, R. L. and Nashelsky, L. (2013). Dispositivos Eletrônicos e Teoria de Circuitos, 11 edn, Pearson Prentice Hall, São Paulo.

CNA, C. d. A. e. P. d. B. (2016). Agropecuária supera obstáculos e segue liderando a economia brasileira em 2016, CNA Brasil. Matéria Digital.

URL: http://www.cnabrasil.org.br/noticias/agropecuariasupera-obstaculos-e-segue-liderando-economiabrasileira-em-2016 
Cunha, J., Teixeira, M. M. and Fernandes, H. C. (2007). Avaliação do espectro de gotas de pontas de pulverização hidráulicas utilizando a técnica da difração do raio laser, Engenharia Agrícola 27(1).

da Cunha, J. P. A. R. (2008). Simulação da deriva de agrotóxicos em diferentes condições de pulverização.

Gothwal, H., Kedawat, S. and Kumar, R. (2011). Cardiac arrhythmias detection in an ecg beat signal using fast fourier transform and artificial neural network, Journal of Biomedical Science and Engineering 4(04): 289.

Haykin, S. (2001). Redes neurais: princípios e práticas, Bookman Editora.

Hipkins, P. A., Grisso, R. D., Wolf, B. and Reed, T. (2009). Droplet chart/selection guide.

Joaquim, M. B. (2010). Processamento digital de sinais.

Macedo, H. and Tipler, P. A. (2000). Física para cientistas e engenheiros: Eletricidade e magnetismo, óptica. $6^{\mathrm{a}}$ edição.

Matos, É. d. R. et al. (2009). Um método para detecção e classificação de curtos-circuitos em redes de distribuição de energia elétrica baseado na transformada de fourier e em redes neurais artificiais.

Matthews, G. (2002). The application of chemicals for plant disease control, Plant pathologist's pocketbook p. 345 .

McRoberts, M. (2011). Arduino básico, São Paulo: Novatec .

Nääs, I. d. A., Campos, L. S., Baracho, M. d. S., Tolon, Y. B. et al. (2008). Uso de redes neurais artificiais na identificação de vocalização de suínos, Engenharia Agrícola .

Nordby, A. and Skuterud, R. (1974). The effects of boom height, working pressure and wind speed on spray drift, Weed Research 14(6): 385-395.

Onuki, D. M. (2005). Sistema de análise em frequência de filtros analógicos, Centro Universitário Positivo, UnicenP, Curitiba: Centro Universitário Positivo. Monografia.

Rodrigues, D. S. (2007). A física do laser, Universidade Federal de Uberlância. Monografia.

Rodrigues, E. B., Abi-Saab, O. J., Gandolfo, M. A., de Oliveira, R. B. and Hasegawa, M. M. (2015). Deriva de equipamentos costais na aplicação de glyphosate., Revista Brasileira de Engenharia Agrícola e Ambiental-Agriambi 19(10).

Rosenblatt, F. (1958). The perceptron: A probabilistic model for information storage and organization in the brain., Psychological review 65(6): 386.

Rufino, C. A. (2011). Desenvolvimento de um sistema para detecção de dispersóides no ar, Master's thesis, Universidade Federal de Lavras, Lavras.
Santos, F. J. (2004). Introdução às séries de fourier, Belo Horizonte: PUC Minas, Instituto de Matemática Pura e Aplicada .

Silva, J. E., da Cunha, J. P. and Nomelini, Q. S. (2014). Deposição de calda em folhas de cafeeiro e perdas para o solo com diferentes taxas de aplicação e pontas de pulverização., Revista Brasileira de Engenharia Agrícola e Ambiental-Agriambi 18(12).

Steden, C. (1992). Untersuchungen zum einflub der tropfengröbe auf die belagsbildung und die biologische wirksamkeit gegen oidium tuckeri berk. an reben, p. 118. Inaugural Dissertation zur Erlangung des Doktorgrades Justus - Universität Gieben, Justus - Liebig, 1992. 